\title{
CICLO DE VIDA PROFISSIONAL E AS CRENÇAS CURRICULARES DE FORMADORES EM CIÊNCIAS E MATEMÁTICA
}

\section{PROFESSIONAL LIFE CYCLE AND THE CURRICULAR BELIEFS OF TEACHERS IN SCIENCE AND MATHEMATICS}

\author{
Letícia Ribeiro Lyra ${ }^{1}$ \\ José Francisco Custódio ${ }^{2}$
}

\begin{abstract}
Resumo: Os professores têm crenças curriculares, que foram construídas ao longo de sua trajetória formativa e profissional. Nesse sentido, temos como objetivo analisar as crenças curriculares de professores formadores que têm diferentes tempos de atuação docente. Realizamos um estudo empírico, com abordagem qualitativa, no qual aplicamos um questionário do tipo escala Likert a 27 docentes que atuam em cursos de Licenciatura em Ciências da Natureza e Matemática de uma universidade federal. Para análise das crenças curriculares e experiência docente selecionamos dez das 40 afirmativas do questionário. As crenças curriculares foram categorizadas em tradicionais ou construtivistas. $\mathrm{O}$ ciclo profissional foi dividido entre 0-3 anos, 4-6 anos, 7-25 anos, 25-35 anos e mais de 35 anos. Os resultados apontam que a maioria dos professores, independentemente do tempo de atuação, apresentam tendência a crenças curriculares construtivistas, embora traços de crenças curriculares tradicionais tenham sido mais encontrados entre professores que atuam há menos de três anos.
\end{abstract}

Palavras-chave: Professores formadores; Crenças curriculares; Ciclo de vida profissional; Educação em Ciências e Matemática.

\begin{abstract}
Teachers have curricular beliefs, which were built along their formative and professional trajectory. In this sense, we aim to analyze the curricular beliefs of teacher educators who have different teaching times. We carried out an empirical study, with a qualitative approach, in which we applied a Likert scale questionnaire to 27 teachers who work in Sciences of Nature and Math teaching courses from a multiple-campus federal university. For the analysis of the curricular beliefs and teaching experience we selected ten of the 40 statements of the questionnaire. Curricular beliefs were categorized into traditional or constructivist. The professional cycle was divided in less than 3 years, 4-6 years, 7-25 years, 25-35 years and more than 35 years. The results show that most teachers, regardless of the time of performance, tend to constructivist curricular beliefs, although traces of traditional curricular beliefs have been found among teachers who have been working for less than three years.
\end{abstract}

Keywords: Teacher training; Curricular beliefs; Professional life cycle; Education in Science and Mathematics.

\footnotetext{
${ }^{1}$ Doutoranda do Programa de Pós-graduação em Educação Científica e Tecnológica da Universidade Federal de Santa Catarina. Professora Assistente da Universidade Federal da Fronteira Sul (UFFS), Chapecó, Santa Catarina, Brasil. E-mail: lerlyra@ uffs.edu.br

${ }^{2}$ Doutor em Educação Cientifica e Tecnológica pela Universidade Federal de Santa Catarina. Professor Associado da Universidade Federal de Santa Catarina (UFSC) e coordenador do Programa de PósGraduação em Educação Científica e Tecnológica da UFSC, Florianópolis, Santa Catarina, Brasil. E-mail: j.custodio@ufsc.br
} 


\section{Introdução}

Os professores formadores ${ }^{3}$ vão se constituindo docentes a partir de sua trajetória acadêmica e profissional, que está fortemente sedimentada pelas suas crenças (PAJARES, 1992). Para esse autor, as crenças não são conscientes e estão vinculadas a aspectos afetivos e valorativos. Elas vão se construindo e se modificando ao longo da vida pelas interações familiares, sociais e educacionais. Essas crenças, “com o tempo, [...] vão se depurando, consolidando-se, entrelaçando-se, formando redes" (BZUNECK; BORSATO, 1999, p. 5), que resultará no sistema de crença pessoal.

Pajares (1992) destaca que as crenças vão se consolidando sem reflexão. Uma vez estabelecidas, tendem a se perpetuar, orientando e interferindo no comportamento e na tomada de decisões diária dos docentes. Segundo Gimeno Sacristán (2000), a epistemologia implícita do professor, que consiste na ideia que esse tem de conteúdo de aprendizagem e conhecimento valioso, o levará a selecionar determinados elementos do currículo oficial, filtrando o que ensinará ou não.

Considerando o exposto, acreditamos que as crenças dos professores terão um importante papel em regular a seleção por parte dos docentes de como e quais conteúdos serão ensinados e aprendidos, como será a avaliação, etc. Fundamentamos essa hipótese em Palma (2009). Segundo esse autor, os professores apresentam crenças curriculares, que se referem ao que o pensa sobre o conteúdo, metodologia, avaliação, etc. Ele define que essas podem ser tradicionais e construtivistas.

Os professores com crenças curriculares tradicionais apresentam uma visão de Ciência como verdade absoluta e inquestionável, a "qual deve ser entregue aos alunos numa versão simples e atualizada" (PALMA, 2009, p.512). Não levam em conta o conhecimento prévio dos alunos e sua metodologia deve ser planejada e seguir uma sequência lógica. Acreditam que a avaliação é para comprovar o nível de conhecimento dos alunos, sendo preferencialmente, por meio de provas escritas (PALMA, 2009).

Pautam-se por uma postura epistemológica empirista-indutivista e positivista (BECKER, 2013) e orientam a apresentação de um currículo enciclopédico, cientificista, conteudista, voltado à memorização e acúmulo de informações (LOPES, 2007). O

\footnotetext{
${ }^{3}$ Entendemos por professores formadores "todos os profissionais envolvidos nos processos formativos de aprendizagem da docência de futuros professores ou daqueles que já estão desenvolvendo atividades docentes" (MIZUKAMI, 2006, p.3). Doravante utilizaremos os termos formadores, docentes, professores como sinônimos de professores formadores de Ciências e Matemática.
} 
docente apresenta um modelo pedagógico diretivo: o professor é quem 'organiza' e ‘transmite' o conhecimento e cabe ao aluno ‘memorizá-lo' (BECKER, 2013). Acredita que todo conhecimento provém da experiência, que está fora do sujeito, por exemplo, no professor e nos livros. Segundo Marsulo e Da Silva (2005, p. 5),

[...] uma das crenças e convicções que perpassam a ação pedagógica dos
professores é a de que ciência é um conjunto de verdades, descobertas por
cientistas, e que saber ciência é memorizar e saber repetir essas verdades ou
parte delas. Esta crença acentua a ideia de que se "é científico é verdadeiro".

Os professores com crenças curriculares construtivistas apresentam uma visão de Ensino de Ciências e Matemática que evidencia conteúdos historicamente contextualizados, provisórios e sujeitos à contestação (MORAES, 2000; BECKER, 2013). A atuação desse professor baseia-se num modelo de pedagogia relacional em que, a partir da atividade e da problematização da sua ação, o estudante constrói seu conhecimento. A metodologia deve ser mais variada e levar em conta a motivação e participação dos alunos. Entendem que a prova escrita não é o único meio de avaliação (PALMA, 2009).

Nessa perspectiva, considera-se que o estudante tem conhecimentos prévios e deve ser considerado seu contexto sociocultural, para que esse construa seu conhecimento (BECKER, 2013; PALMA, 2009). Esses professores baseiam-se numa atitude epistemológica interacionista (BECKER, 2013) em que há valorização do conteúdo, mas também, esses não são vistos como prontos e acabados, sendo continuamente revistos e construídos $\left(\right.$ MORAES, 2000) ${ }^{4}$. De acordo com Moraes (2000), são essas as características de professor construtivista: atitude pesquisadora, questionadora, mediadora, problematizadora, interdisciplinar e dialógica. Incluímos também a capacidade do professor ter flexibilidade para incorporar conteúdos além dos estabelecidos pelo currículo oficial.

Neste sentido, se faz imprescindível compreender qual o tipo de crença curricular (tradicional ou construtivista) que o formador de professores de Ciências e Matemática traz em sua prática docente, pois esse definirá um modelo de Ciência e como esta deve ser ensinada e aprendida pelos estudantes.

Considerando que as crenças têm diferentes origens: pela experiência própria, observação de alguém, indiretamente (leitura, palestras, documentos oficiais, material didático, entre outras fontes), pela interação com autoridades (professores e

\footnotetext{
${ }^{4}$ Moraes (2000) apresenta uma discussão sobre as multiplicidades de 'construtivismos' e destaca as três principais correntes.
} 
pesquisadores), entre outras formas (PAJARES, 1992; MICCOLI, 2010), acreditamos que haja diferenças entre as crenças curriculares de formadores com diferentes tempos de atuação docente, considerando essas vivências. Entendemos que as crenças curriculares do formador iniciante na docência serão constituídas pelo que esse aprendeu ao longo da sua trajetória como estudante na educação básica e na licenciatura, sendo que o modelo de formação inicial que teve terá grande influência sobre sua atuação (PAJARES, 1992). Enquanto os formadores mais experientes tenderão a atuar baseando-se em crenças curriculares construídas na sua trajetória pessoal e profissional. Segundo Gimeno Sacristán (2000), a socialização profissional, produzida pela convivência com os companheiros, é fator para disseminação de atitudes e crenças curriculares, os conhecimentos, a avaliação, etc.

Em linhas gerais, acreditamos que a trajetória do ciclo de vida profissional do formador, tanto a vivência como aluno da educação básica e de licenciatura, quanto a experiência docente possibilita a construção de crenças curriculares. Neste sentido, propomos a seguinte questão de pesquisa: há relação entre as crenças curriculares dos professores formadores e o tempo de atuação docente?

\section{Crenças e currículo: apontamentos}

“As crenças são os melhores indicadores quanto às decisões que indivíduos tomam ao longo da vida" (PAJARES, 1992, p.307, tradução livre). Considerando-se que essas são uma das formas de pensamento humano, acreditamos que o professor atua de acordo com elas sem ter, muitas vezes, suficiente reflexão da influência dessas sobre sua prática (PAJARES, 1992; MIZUKAMI, 2006). Por terem influência nas ações dos professores, elas têm recebido uma grande atenção por parte dos investigadores educacionais sendo amplamente discutidas na literatura, nacional e internacional (FUNDA SAVASCI-ACIKALIN, 2009). Destacamos que, segundo Palma (2009), as crenças podem se manifestam também por meio de declaração verbal e escrita, sendo essa última a que privilegiaremos em nossa análise.

Uma parte do sistema de crenças das pessoas é composta pelas crenças educacionais (PAJARES, 1992). Essas são elaborações internas, portanto individuais, sobre como os professores concebem o currículo, os processos de ensinar e aprender, o conhecimento didático-pedagógico, convicções sobre o seu papel de professor, a motivação do aluno, inteligência, avaliação, rendimento escolar, a função da escola, o 
processo de desenvolvimento do estudante, sua profissão, a família do aluno, o sistema escolar, a gestão da escola, o seu sentimento de autoeficácia profissional e pessoal, a disciplina ou os conteúdos específicos e a natureza do conhecimento científico.

Considerando-se que há uma pluralidade de crenças educacionais que possam exercer influência sobre a prática do professor, definimos por destacar as crenças curriculares. As crenças curriculares referem-se ao que o professor crê que deve fazer e o que crê que faz (PALMA, 2009), ou seja, referem-se o que o professor planeja em relação ao conteúdo e como este deve ser ensinado e aprendido. Segundo Ariza (1995), cada professor oferece um currículo diferente aos alunos por terem crenças diferentes. Nesse sentido, essas têm um importante papel na maneira como o professor é em sala de aula.

Tobin e McRobbie (1997) desenvolveram um estudo no qual examinaram a visão de Natureza da Ciência (NdC) de um professor e de estudantes do ensino médio na Austrália quanto ao ensino e à aprendizagem de Química e sua relação com currículo oficial. Identificaram que o currículo oficial era apresentado como um catálogo de fatos a serem memorizados e de solução de algoritmos. A prática do professor foi identificada com controle das decisões curriculares e centrada na figura de 'autoridade científica', as crenças sobre aprendizagem da $\mathrm{NdC}$ eram marcadas pela visão positivista do conhecimento, o que influenciou na visão dos estudantes, que apresentaram visões semelhantes às do professor.

Considerando o exposto, faremos alguns apontamentos sobre o currículo. Para Gimeno Sacristán (2000), o currículo ${ }^{5}$ consiste numa práxis complexa porque se expressa em cruzamentos de práticas diversas: filosóficas, epistemológicas, científica curricular, políticas, administrativas, valores sociais, entre outras fontes que geram crenças que irão penetrando na atuação docente. Para o autor (2000) o currículo é composto por diferentes dimensões, que devem ser vistas como um processo interligado:

1) currículo prescrito e regulamentado é estabelecido pelas instâncias políticas e administrativas superiores, por meio de um currículo oficial;

2) currículo planejado, quando o currículo prescrito é 'traduzido' por meio de guias, para o público que irá implementá-lo;

3) currículo moldado, que é quando o professor prepara o seu plano de ensino baseando-se no currículo prescrito. Esse autor aponta que a epistemologia implícita do

\footnotetext{
${ }^{5} \mathrm{O}$ termo currículo é polissêmico. Utilizamos como principal referencial os estudos GimenoSacristán (2000)
} 
professor, sua ideia do que é conteúdo de aprendizagem e conhecimento valioso, o levará a selecionar determinados elementos do conteúdo.

4) currículo em ação é quando os currículos anteriormente descritos (currículo prescrito, planejado e moldado) são postos na prática docente. Está presente na prática do professor na sala de aula por meio do discurso, das atividades que escolhe para ensinar o conteúdo, entre outras maneiras. O currículo em ação presente na interação professoraluno engendra diversos efeitos (cognitivos, afetivos, morais) sobre estes sujeitos.

5) currículo avaliado são os critérios de avaliação interna (aprendizagem dos estudantes) e externas (políticas de avaliação).

Destacamos o currículo em ação, em que o professor manifesta suas crenças curriculares na atuação docente, por meio das atividades propostas, nas aulas de laboratório, nos textos que utiliza. O professor, ao atuar, 'explicita' as crenças, ou seja, demonstra o currículo oculto (APPLE, 2006).

Para esse autor, o currículo oculto refere-se às normas e aos valores "que são implicitamente, mas eficazmente, ensinados nas escolas e sobre os quais o professor em geral não fala nas declarações de metas e objetivos" (APPLE, 2006, p.127). Destaca que a aprendizagem incidental, que é relativa à interação dos professores com o que os alunos são expostos, os leva a aprender mais do que ensino 'oficial'.

Considerando-se o efeito do currículo oculto na formação inicial, podemos entender que

[..] será o currículo oculto de formação de professores e o adquirido por experiência prévia os únicos elementos responsáveis para sua bagagem [dos futuros professores] neste componente da formação profissional. Pelo simples fato de não se tratar esses dilemas epistemológicos na formação do professorado, se reforçam as concepções prévias dominantes (GIMENO SACRISTÁN, 2000, p.182).

Ariza (1995, p.12, tradução livre) sinaliza a presença de "um currículo oculto que favorece uma imagem fortemente positivista do conhecimento científico”. Esse autor também ressalta que um dos meios de construção da imagem deformada sobre qualquer Ciência está presente no currículo oculto, que tende a repassar mitos sobre a Ciência: do progresso científico, que as explicações científicas são verdades e pautadas na razão e na infalibilidade dos especialistas (ARIZA,1995). Esses mitos impregnam o currículo oficial na maneira como os professores ensinam a Ciência, em geral, seguindo o modelo positivista.

Em linhas gerais, as crenças condicionam o processo de decisão didáticopedagógica dos professores, influenciando antes, durante e após sua atuação docente 
(RAMÍREZ, 2005). Nesse sentido, entendemos que há impacto das crenças curriculares e como esse é tratado pelo professor terá influência na formação dos licenciandos sobre o Ensino-aprendizagem da Ciência.

\section{Ciclo de vida profissional do professor: um processo de (re)construção de crenças curriculares}

Os professores apresentam um ciclo de vida profissional (HUBERMAN, 1995). De acordo com esse autor, a primeira fase do ciclo é a entrada na carreira, com duração de aproximadamente três anos, em que o professor vai tateando sua prática docente e confrontando-a com a realidade. $\mathrm{O}$ autor aponta que nessa fase os professores oscilam entre a sobrevivência e/ou descoberta. A sobrevivência marca um questionamento do professor sobre sua competência para lidar com a atividade docente, administrando o real e o ideal. A descoberta caracteriza-se por sentir entusiasmo em pertencer a um grupo social.

Segundo Huberman (1995), os percursos individuais divergem mais a partir da segunda fase, que é a estabilização (4-6 anos), quando há a consolidação de um repertório pedagógico e o professor se foca no ensino.

A terceira fase (7-25 anos de docência) proposta por Huberman (1995) é de diversificação ou pôr se em questão, em que há um certo ativismo profissional (lançamse novas formas de avaliação, metodologias, entre outros) ou trata-se de uma fase de questionamento de si, quando a sensação de rotina ou crise existencial fica mais evidente, especialmente, quando o professor faz um balanço da vida profissional e os avalia como tendo mais perdas do que ganhos profissionais.

Para Huberman (1995), a penúltima fase (25-35 anos) é da serenidade e distanciamento afetivo. A serenidade caracteriza-se pelo professor aceitar como é e não como os outros querem que seja. Apresenta uma sensação de confiança e mais tolerância. O distanciamento afetivo caracteriza-se pela resistência às inovações, por uma nostalgia do passado, entre outros sentimentos.

Por fim, a fase do desinvestimento (35-40 anos), quando há o recuo e a interiorização, no final da carreira profissional. Pode ser vivenciada como um período sereno ou amargo, dependendo das autoavaliações que o professor faz do seu percurso profissional. A serenidade é quando o professor avalia seu percurso profissional como 
positivo. Enquanto no desencantamento, há sentimento de frustração pelas experiências vivenciadas.

Destacamos também outras considerações sobre o tempo de atuação profissional dos professores. Segundo Pajares (1992), a entrada de professores na docência tende a ser disfuncional porque tendem a valorizar os aspectos afetivos e desvalorizar os cognitivos/acadêmicos. Nessa mesma linha de pensamento, Crahay e colaboradores (2006, p. 335) apontam que

[...] para a maior parte dos professores iniciantes, a inserção profissional assemelha-se a um desencantamento brutal, no decorrer do qual lhes é necessário renunciar às 'belas ideias' e às crenças que tiveram no fim de sua formação inicial, ou antes mesmo de concluí-la.

Tardif (2014), também trará apontamentos sobre o ciclo profissional. Segundo ele, os anos iniciais da atuação serão fundamentais para o estabelecimento dos saberes docentes. Nesse período, o professor adquire a experiência fundamental como docente que se tornará em sua 'personalidade profissional' marcando sua maneira de ensinar. Para ele, a primeira fase (1-3 anos) é quando o professor escolhe a profissão e atua mais utilizando-se de tentativas e erros.

Tardif (2014) aponta que fase seguinte é de estabilização e consolidação da carreira (4-6 anos), quando há um sentimento de pertença a um corpo profissional e a independência, sentimento de competência pedagógica, quando o professor investe na profissão e a visualiza a longo prazo. Nesse período, também se volta mais aos alunos e suas dificuldades e menos em si e na matéria, pois já obteve uma maior segurança profissional.

Na linha de estudos sobre profissionalização docente Isaia, Maciel e Bolzan (2011) realizaram estudo com 40 professores iniciantes em duas instituições de ensino superior pública e privada ${ }^{6}$ e constataram que os primeiros anos de docência são determinantes para a formação do profissionalismo docente. As autoras dividem a carreira docente em inicial (0-5 anos), intermediária (6-15 anos) e final (16 em diante). Destacam que a entrada na docência universitária é acidental, em que os professores saem da pósgraduação sem preparo para atuar nesse nível de ensino. Quando entram na docência, utilizam-se de sua experiência como discente, reproduzindo modelos vivenciados e da identificação com ex-professores.

\footnotetext{
${ }^{6}$ No artigo, as autoras não citam qual o universo formativo dos professores universitários participantes da pesquisa.
} 
As autoras ressaltam que a aprendizagem do ofício de ensinar depende de "bases epistemológicas e práticas [que] lhes são desconhecidas" (ISAIA; MACIEL; BOLZAN, 2011, p.431) e que vão sendo apropriadas e interiorizadas por meio da cultura docente e acadêmica. Sinalizam que a transição entre professor em formação para autônomo não é um processo linear e fácil, sendo marcado pelos sentimentos dúbios de insegurança e empolgação pela docência.

Em linhas gerais, identificamos, nesses estudos, que os professores passam por transformações em seu ciclo profissional e que acreditamos que sejam determinantes para a (re)construção de suas crenças curriculares. Para investigar se há diferença entre as crenças curriculares dos professores iniciantes e daqueles com mais experiência na docência, utilizamos da periodização proposta por Huberman (1995): 0-3 anos, 4-6 anos, 7-25 anos, 25-35 anos e 35-40 anos ou mais. A escolha por essa periodização deve-se a entendermos que melhor atenderia ao público-alvo desta investigação.

\section{Percurso metodológico}

Esse artigo é parte de uma pesquisa empírica, referente às crenças educacionais de professores formadores, que está sendo desenvolvida no doutoramento de um dos autores. Uma das estratégias metodológicas dessa pesquisa, consistiu na aplicação de um questionário do tipo Likert com 40 afirmativas, que variavam numa escala de discordo totalmente a concordo totalmente, a 27 professores formadores, que atuam em cursos de licenciatura em Ciências da Natureza e Matemática de uma universidade federal multicampi.

Essa universidade foi criada na última década como parte do plano de interiorização das instituições de ensino superior e a escolha por tê-la como lócus da pesquisa deve-se a essa ter a formação de professores como princípio norteador do Projeto Pedagógico Institucional.

Conforme Barcelos (2001), existem três abordagens para o estudo das crenças: normativa, metacognitiva e contextual. Utilizaremos a abordagem normativa pois essa infere as crenças por meio de um conjunto de afirmações, tais como os questionários com Escala tipo likert. Também, nos apoiamos em De Juanas (2012), que aponta que o método mais comum em pesquisas sobre crenças é a Escala tipolikert.

Segundo Barcelos (2001), o questionário nos auxilia a ter uma visão mais geral das crenças presentes entre o coletivo de professores e a analisar o que dizem fazer. Para 
Palma (2009), podemos investigar o pensamento do professor por meio do questionário. Segundo ele, o "questionário estruturado nos indica com o que os professores se identificam” (PALMA, 2009, p. 508, tradução livre). Por isso, entendemos que seja um instrumento interessante para responder nossa questão de pesquisa: se há relação entre as crenças curriculares dos professores formadores e o tempo de atuação docente.

Porém, não desconsideramos que esse instrumento tem limitações quanto a entender essas crenças na atuação docente. Esse instrumento nos indica o que os professores acreditam que deva ser sua prática e não sua prática em si (PALMA, 2009).

Para a elaboração do questionário, baseamo-nos em dois instrumentos: Inventario de Creencias Pedagógicas y Científicas de Profesores (INPECIP), elaborado por Porlán ${ }^{7} \mathrm{e}$ Questionário epistemológico para estudantes do ensino Universitário (QEEU), de Marlene Schommer ${ }^{8}$. Após a elaboração desse, discutimos as afirmativas num grupo de pesquisa que trata sobre a temática e submetemos à validação semântica por cinco professores universitários e pedagogos, não participantes da pesquisa, a fim de obter confiabilidade desse instrumento.

O questionário continha 40 afirmativas que avaliavam as crenças educacionais de natureza epistemológica e didático-pedagógica. Dentre essas, selecionamos oito afirmativas que tratavam de crenças curriculares, para que pudéssemos atingir nosso objetivo que era identificar e analisar as crenças curriculares de formadores que têm diferentes tempos de atuação docente. Escolhemos essas afirmativas pois tratam sobre conteúdo e metodologia, dois aspectos apontados por Palma (2009) como estruturantes das crenças curriculares.

Logo em seguida, criamos duas grandes categorias: crenças curriculares tradicionais e crenças curriculares construtivistas. Para a categorização dessas crenças utilizamos os aportes teóricos de Palma (2009), Becker (2013) e Moraes (2000). Em linhas gerais, as crenças curriculares tradicionais são aquelas em que o professor apresenta uma epistemologia empirista e modelo pedagógico diretivo e as crenças curriculares construtivistas baseia-se numa epistemologia interacionista e o modelo pedagógico relacional.

Também selecionamos duas afirmativas que tratavam sobre a experiência e atuação docente com objetivo de complementar os dados sobre esses aspectos. O critério

\footnotetext{
${ }^{7}$ Não localizamos a tese doutoral de Porlán, em que apresenta o inventário originalmente. Neste sentido, optamos por utilizar as fontes que o referenciam Ramírez (2005).

${ }^{8}$ QEEU nas versões em inglês e português está em Gonçalves (2002).
} 
de organização da periodização do ciclo profissional seguiu o proposto por Huberman (1995).

Organizamos as respostas entre 'concordantes' - que incluía as afirmativas 'concordo' e 'concordo plenamente' - e 'discordantes' - que incluía 'discordo' e 'discordo totalmente' - e analisamos buscando identificar se havia diferenças das crenças curriculares entre os formadores ao longo do ciclo profissional.

Os resultados foram analisados qualitativamente, uma vez que concordamos com Pajares (1992), que aponta que a abordagem qualitativa é relevante e adequada para análise das crenças. Nesse sentido, consideramos importante salientar que o objetivo da presença de dados numéricos (números e porcentagens) e termos quantitativos (maioria, menos, etc.) referentes às respostas apresentadas no questionário é de somente fornecer indicadores na análise das informações fornecidas pelos docentes.

\section{Análise e discussão dos resultados}

Dos 27 respondentes, temos nove professores da Biologia (33\%), cinco da Física (19\%), dez da Matemática (37\%) e três da Química (11\%), desses55\% são homens e 45\% mulheres, sendo que as mulheres prevalecem nas áreas de Biologia e entre os homens há um equilíbrio entre as áreas de Física e Matemática. Quanto à idade, a maioria (52\%) está entre 30-39 anos, caracterizando-se por um grupo de jovens professores, com alta qualificação profissional sendo que 74\% têm doutorado e 33\% têm pós-doutorado.

Dos respondentes, $70 \%$ são licenciados e $15 \%$ têm bacharelado e licenciatura. Esse é um dado importante, pois contradiz as pesquisas que apontam a prevalência de professores bacharéis nas licenciaturas (SOUZA, 2011; MIZUKAMI, 2006). A maioria dos professores (67\%) se formou entre 2000-2009. Esse dado pode sinalizar que tenham tido experiências formativas com uma visão de ciência como construção histórica, coletiva, relacionada à sociedade e contrária ao empirismo lógico, uma vez que essa tendência está presente nas Diretrizes Curriculares Nacionais para Formação de Professores da Educação Básica - DCN (BRASIL, 2002a) e as Diretrizes Curriculares dos Cursos de Ciências da Natureza e Matemática -DC (BRASIL, 2002b; 2002c; 2002 d; 2003), que já estavam em vigor, quando a maioria deles se graduou.

A maioria (52\%) atuou na rede privada sendo os professores da área de Matemática, os que mais atuaram nessa rede (70\%). Dos respondentes, $43 \%$ atuou menos que três anos na rede privada. A maioria dos respondentes (56\%) têm entre 7-25 anos de 
atuação como docentes, caracterizando a fase de diversificação ou se pôr em questão (HUBERMAN, 1995), sendo a maioria desse tempo destinado à atuação no ensino público. Destacamos que todos os docentes de Química estão contidos nesse tempo de atuação (7-25 anos) e os professores de Física são os que atuam há menos tempo: 60\% têm até 6 anos de atuação. Os professores de Matemática (70\%) são os que atuam há mais tempo, entre 7 a mais de 35 anos, sendo os professores mais experientes do coletivo.

Dentre as oito afirmativas do questionário que versavam sobre crenças curriculares, selecionamos três, que tratavam sobre crenças com viés tradicional. Essas afirmativas constavam a centralidade no conteúdo e na ação do professor, sendo consideradas tradicionais (Quadro 1):

\begin{tabular}{|c|c|}
\hline $\begin{array}{c}\text { Número } \\
\text { da } \\
\text { Afirmativa }\end{array}$ & Descrição da afirmativa \\
\hline 7 & 'O trabalho em sala de aula deve estar organizado fundamentalmente em torno dos \\
conteúdos da área de conhecimento que você leciona'
\end{tabular}

Quadro 1: Descrição das afirmativas referentes às crenças curriculares tradicionais.

Fonte: Elaborado pelos autores.

Dessas afirmativas, temos os seguintes dados (Figura 1).

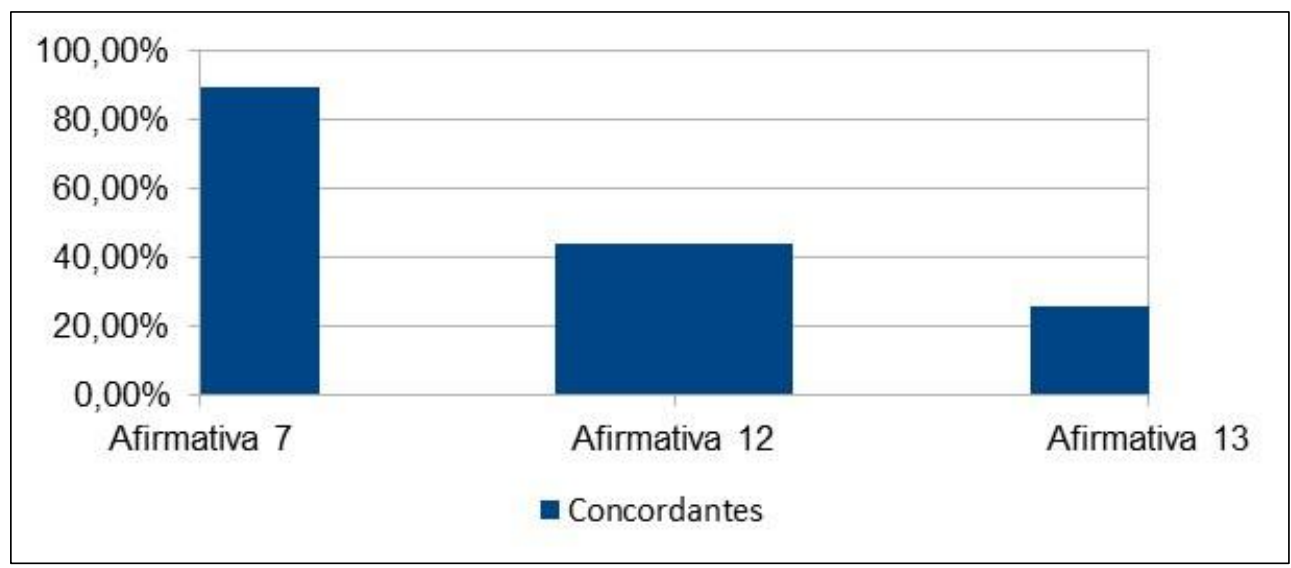

Figura 1: Porcentagem de concordantes em relação às afirmativas referentes às crenças curriculares tradicionais.

Fonte: Elaborado pelos autores.

De acordo com a Figura 1, identificamos a porcentagem de concordantes por afirmativa, sendo a afirmativa 7 a que mais tem a adesão dos respondentes e a afirmativa 13 a que menos é aceita. Se somarmos todas as respostas concordantes teremos $53 \%$ dos 
respondentes, o que aponta que a maioria dos professores tendem a aceitar afirmativas tradicionais.

Quanto a distribuição das respostas concordantes em relação às afirmativas e ao tempo de atuação profissional temos os seguintes dados (Figura 2$)^{9}$.

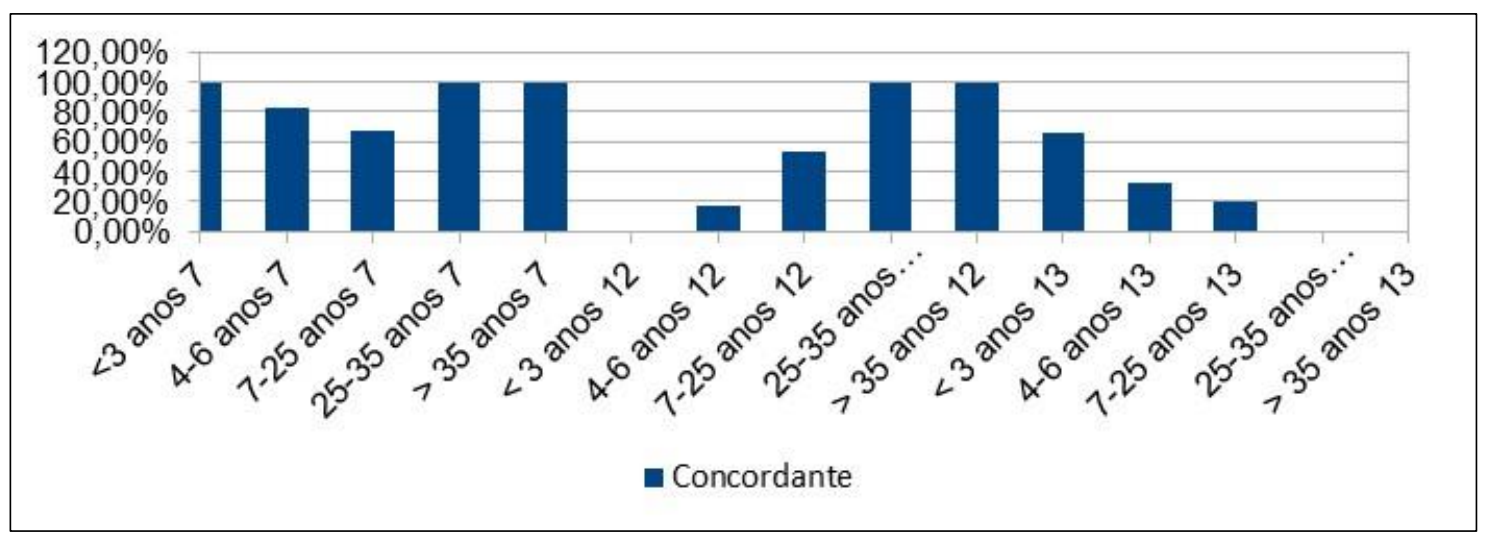

Figura 2: Crenças curriculares tradicionais em relação ao tempo de atuação.

Fonte: elaborado pelos autores.

Analisando a Figura 2, identificamos que não há grande variação entre os professores ao longo do tempo de atuação profissional em relação às afirmativas com viés tradicional. Destacamos que os professores mais experientes são os mais concordantes com esse viés tradicional.

Analisando as Figuras 1 e 2, vemos que a maioria dos professores (89\%) independente do tempo de atuação são concordantes com a afirmativa 7, 'O trabalho em sala de aula deve estar organizado fundamentalmente em torno dos conteúdos da área de conhecimento que você leciona', apontando para uma visão racionalidade técnica focada no conteúdo, confirmando o que Lopes (2007) destacou em seu estudo sobre currículo de Ciências. A autora aponta que há a permanência de visão enciclopedista, cientificista e mitificação da prática real de produção de conhecimento científico, sendo marcado pelo empirismo e positivismo. Sendo que todos os professores que atuam há menos de três anos e há mais de 25 anos em diante são concordantes com nessa afirmativa, o que parece apontar que tanto os novatos, quanto só mais experientes tendem a centralizar o conteúdo.

\footnotetext{
${ }^{9} \mathrm{O}$ eixo vertical indica a porcentagem das respostas. O eixo horizontal representa a variação das respostas por grupo do tempo de atuação em cada questão. As respostas dos professores que têm menos de três anos de atuação foram indicadas na figura como $<3$ anos e os que atuam a mais de 35 anos são indicados como $>35$ anos. Os grupos foram seguidos pelo número da questão que estava sendo avaliado. Por exemplo, <3 anos 7 representa as respostas dos professores que atuam há menos de 3 anos em relação à questão 7 . E assim, sucessivamente. Essa formatação será utilizada nas figuras 2 e 4.
} 
A maioria dos professores (56\%) discordam da afirmativa 12, 'O conteúdo ensinado na (s) disciplina(s) que leciona são os mais relevantes de serem aprendidos pelos licenciandos', o que, contrariando a resposta anterior, demonstra uma tendência a não aceitar o viés conteudista e enciclopédico. Porém, todos os professores que atuam há mais de 25 anos concordam com essa afirmativa, o que aponta para um olhar mais determinante do conteúdo, confirmando as respostas desses mesmos respondentes na afirmativa 7 .

A maioria dos professores (74\%) são discordantes da afirmativa 13, 'Os licenciandos não devem intervir diretamente na programação e avaliação das atividades da disciplina'. Sendo que os professores que atuam há mais tempo (7 anos em diante) são os mais discordantes, o que aponta para uma docência em que os licenciandos têm mais autonomia. E todos os professores que atuam há menos de três anos são concordantes com a afirmativa apontando para uma tendência mais tradicional, em que há a centralidade do professor em definir quais conteúdos serão ensinados ou não.

Dentre as oito afirmativas que tratavam das crenças curriculares, seis versavam sobre crenças com viés construtivista. As afirmativas traziam a flexibilidade curricular com a inclusão de conteúdos que extrapolavam o currículo oficial e mudança desse, consideradas crenças construtivistas (Quadro 2):

\begin{tabular}{|c|c|}
\hline $\begin{array}{l}\text { Número da } \\
\text { Afirmativa }\end{array}$ & Descrição da afirmativa \\
\hline 3 & $\begin{array}{c}\text { ‘É importante discutir sobre epistemologia com os licenciandos mesmo que esse conteúdo } \\
\text { não esteja presente na ementa da(s) disciplina(s) que leciona’ }\end{array}$ \\
\hline 9 & $\begin{array}{l}\text { 'É importante discutir sobre aprendizagem com os licenciandos mesmo que esse conteúdo } \\
\text { não esteja presente na ementa da(s) disciplina(s) que leciona' }\end{array}$ \\
\hline 20 & $\begin{array}{l}\text { 'É importante discutir sobre ensino com os licenciandos mesmo que esse conteúdo não } \\
\text { esteja presente na ementa da(s) disciplina(s) que leciona' }\end{array}$ \\
\hline 39 & $\begin{array}{l}\text { 'É importante discutir com os licenciandos questões contemporâneas que envolvam } \\
\text { Ciência, Tecnologia e Sociedade (CTS), mesmo que esses não estejam na(s) ementa(s) } \\
\text { da(s) disciplina(s) que leciona' }\end{array}$ \\
\hline 40 & $\begin{array}{c}\text { 'Você se considera capaz de implementar mudanças curriculares na(s) disciplina(s) que } \\
\text { leciona' }\end{array}$ \\
\hline
\end{tabular}

Quadro 2: Descrição das afirmativas referentes às crenças curriculares construtivistas.

Fonte: Elaborado pelos autores.

De acordo com a Figura 3, identificamos que a maioria dos professores são concordantes com as afirmativas que apresentam crenças curriculares construtivistas. 

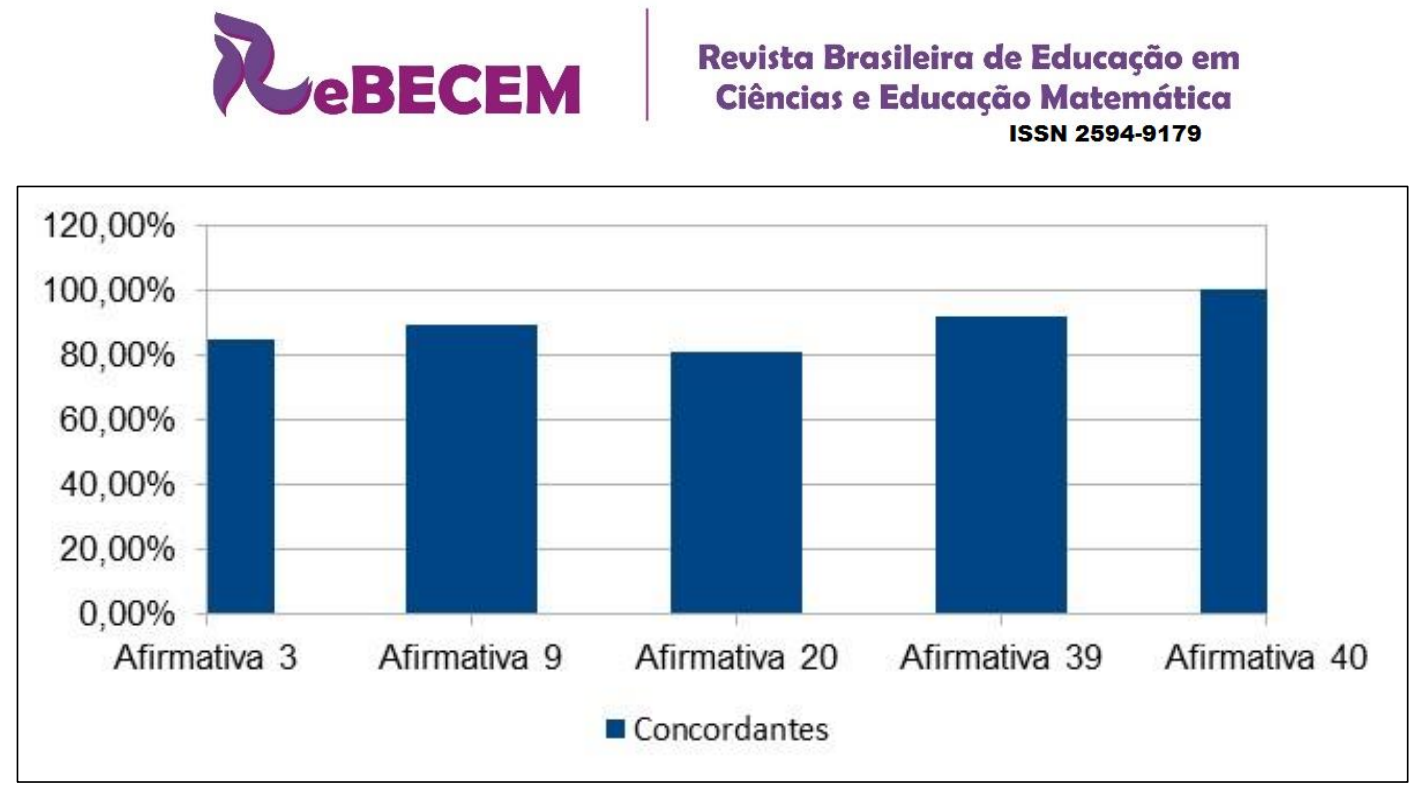

Figura 3: Porcentagem de respostas concordantes em relação às crenças curriculares construtivistas. Fonte: elaborado pelos autores

Com relação a porcentagem de concordantes com crenças curriculares construtivistas ao longo do tempo de atuação profissional temos os seguintes dados (Figura 4).

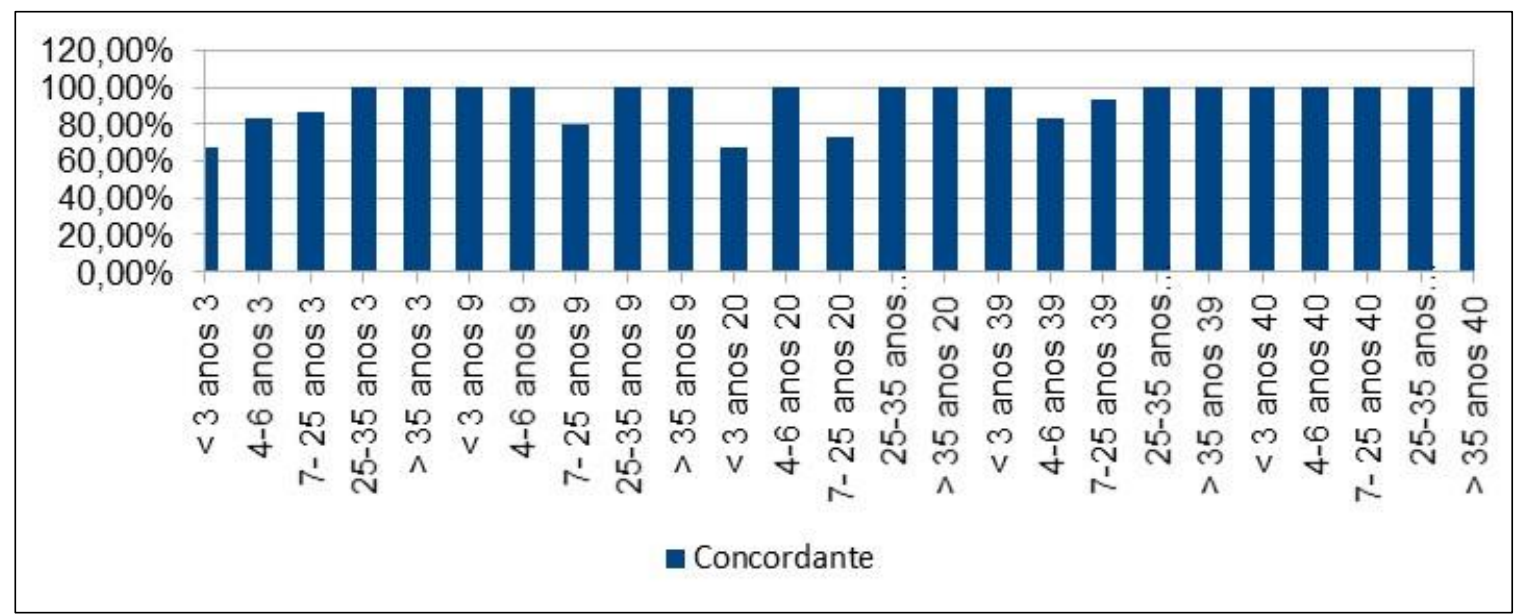

Figura 4: Crenças curriculares construtivistas em relação ao tempo de atuação.

Fonte: elaborado pelos autores

Nessa Figura4, podemos identificar que os professores mais experientes (mais de 25 anos de atuação) são os mais concordantes, o que contraria os dados anteriores. Uma hipótese é que por estarem no fim de carreira tragam um olhar, ora tradicional, que provavelmente reflete a formação inicial que tiveram, ora mais construtivista, que reflete mudanças no olhar o currículo produzidas pela experiência.

Analisando ambas as Figuras (3 e 4), identificamos que a maioria dos professores (85\%) concordam com a afirmativa 3, 'É importante discutir sobre epistemologia com os licenciandos mesmo que esse conteúdo não esteja presente na ementa da(s) disciplina(s) que leciona'. Destacamos que os professores mais novatos são os que menos concordam com essa afirmativa, apontando para uma prática mais tradicional, conforme assinalado 
anteriormente. À medida que vão avançando no tempo de atuação vemos que todos passam a concordar quanto à importância de se discutir a epistemologia, tema presente nas DC dos cursos de Ciências da Natureza e Matemática (BRASIL, 2002b; 2002c; 2002 d; 2003). Destacamos que todos os professores que atuam há mais tempo (mais de 25 anos) são concordantes, o que pode nos apontar para crença curricular mais construtivista em que as teorias são entendidas como históricas e contextualizadas.

A maioria dos professores independente do tempo de atuação (89\%) são concordantes com a afirmativa 9, 'É importante discutir sobre aprendizagem com os licenciandos mesmo que esse conteúdo não esteja presente na ementa da(s) disciplina(s) que leciona', sendo que somente alguns professores (20\%) que atuam entre 7-25 anos são discordantes, porém, é um número inexpressivo diante dos dados totais. Consideramos esse dado muito importante, considerando que o conhecimento pedagógico do conteúdo (SHULMAN, 2014) deve ser tratado nos cursos de formação docente.

A maioria dos professores $(81 \%)$ independente do tempo de atuação é concordante com a afirmativa 20, 'É importante discutir sobre ensino com os licenciandos mesmo que esse conteúdo não esteja presente na ementa da(s) disciplina(s) que leciona' sendo que os professores iniciantes, até três anos e os que têm entre 4-6 anos, destoam pois são discordantes dessa afirmativa. Esses dados chamam a atenção pois, conforme já apontamos, esses jovens professores devem ter tido em sua formação debates da importância do formador integrar conhecimentos específicos com didáticos, conforme previsto nas DCN (BRASIL, 2002 a) e DC (BRASIL, 2002b; 2002c; 2002 d; 2003).

A maioria dos professores (92\%) independente da área de atuação é concordante com a afirmativa 39, 'É importante discutir com os licenciandos questões contemporâneas que envolvam Ciência, Tecnologia e Sociedade (CTS), mesmo que esses não estejam na(s) ementa(s) da(s) disciplina(s) que leciona'. Destacamos que todos os professores que atuam há menos de três anos e os que atuam há mais de 25 são concordantes, o que parece apontar que os extremos entendem a relevância das questões CTS na formação de professores. Esses dados, podem sinalizar um avanço, considerando que o estudo de Díaz et al (2002) aponta que a inserção de temas CTS e da NdC na formação inicial é insuficiente.

Todos os professores independente do tempo de atuação concordam com a afirmativa 40, 'Você se considera capaz de implementar mudanças curriculares na(s) disciplina(s) que leciona'. Esse dado é muito significativo, pois desconstrói o modelo de 
racionalidade técnica, em que em que o professor era meramente um organizador do conteúdo (MACHADO, 2009; TARDIF, 2014).

Em relação a experiência docente selecionamos duas afirmativas 19 e 33. Os resultados apontam que quase a totalidade dos professores (92\%) independente da área de atuação concordam com a afirmativa 19, 'A experiência em sala de aula alterou sua maneira de entender o ensino e aprendizagem de conhecimentos científicos'. Os professores que atuam entre 4-6 anos e os que têm mais de 25 anos de atuação concordam totalmente. Por outro lado, os professores iniciantes (com menos de três anos) são os mais discordantes (33\%) dessa afirmativa. Acreditamos que esses dadossugerem que esses professores novatos ainda não se reconhecem com um saber experiencial (TARDIF, 2014), o qual é construído nos anos iniciais e estabelecido enquanto trabalham sendo compartilhados pelo coletivo de professores, quando aprendem os 'macetes' sobre ensino e aprendizagem.

A maioria dos professores (74\%) discorda da afirmativa 33, 'Professores mais experientes estão mais preparados do que professores recém-formados para ensinar conteúdos científicos'. Esses dados do coletivo de professores diferem do que Shulman (2014) destaca sobre o conhecimento que os professores adquirem quando se tornam especialistas difere daqueles dos principiantes. Um aspecto interessante é que as porcentagens vão se elevando, até que todos os professores que atuam entre 25-35 anos discordam e esse número cai pela metade entre os com mais de 35 anos de atuação. Ou seja, para $50 \%$ dos professores que atuam há mais de 35 anos, a experiência é um diferencial. Esse é um dado interessante que parece apontar para sentimento de serenidade de acordo com Huberman (1995). Em linhas gerais, a experiência docente é entendida por esses professores que atuam há mais de 35 anos como um diferencial na prática docente.

Diante dos resultados, entendemos que há uma tendência a uma crença curricular mais construtivista entre os professores. Podemos inferir que os professores mais novatos (menos que três anos) tendem a ter crenças curriculares mais tradicionais. E à medida que vão tendo mais tempo de atuação, vão apresentando mais tendências construtivistas em relação à inclusão de temas (Epistemologia, CTS, Ensino e Aprendizagem), à flexibilidade no currículo, na programação e avaliação. Porém, os professores mais experientes (mais de 35 anos) tendem a ser mais tradicionais quanto aos conteúdos disciplinares. 
Em linhas gerais, os resultados apontam que a maioria dos formadores atuam de 7-25 anos, o que Huberman (1995) denomina da fase de diversificação ou de questionamento de si. Com esses dados, acreditamos que os professores nessa faixa do ciclo profissional apresentam a fase de diversificação, considerando que em todas as respostas desse grupo prevaleceu crença curricular construtivista.

Também identificamos uma tendência de crença curricular construtivista em outras fases do ciclo profissional, mas não significa que esses apresentam-nas nas suas ações, pois o que dizem fazer não necessariamente é o que fazem (PALMA, 2009). Também, observamos que essas oscilam com as crenças curriculares tradicionais, em várias respostas. Temos a hipótese que a prevalência de formação em licenciatura desses professores seja um diferencial desse grupo de respondentes, em relação às crenças curriculares.

\section{Considerações finais}

A conclusão mais relevante desse estudo é que identificamos que as crenças curriculares desse coletivo de professores passaram de tradicionais à construtivistas em relação ao tempo de atuação docente. Esses resultados contradizem o que Praia e Cachapuz (1994) identificaram em sua pesquisa com professores do ensino secundário, em que independente do tempo de atuação e da área que atuavam, aqueles professores apresentam uma visão empirista-indutivista de Ciência, sendo divulgada como "aproblemática", "ahistórica", descontextualizada, elitista e individualista. Visão confirmada em outras pesquisas da área de educação científica (GIL PÉREZ et al., 2001; CACHAPUZ et al., 2011; COSTA et al., 2017).

Temos como hipótese que à medida que os professores avançaram no seu ciclo de vida profissional foram alterando suas crenças curriculares. Porém, não podemos afirmar isso pois teríamos que ter realizado um estudo longitudinal com esses professores. Uma explicação plausível é que os formadores mais experientes já possuíam crenças com viés mais construtivistas desde sua iniciação docente e que esses mais jovens possam ter sido reforçados em crenças mais tradicionais sobre o currículo, que já vinham construindo antes da inserção profissional. $\mathrm{O}$ que pode apontar que a formação inicial e a experiência não tenham conseguido alterá-las, conforme já apontado por Pajares (1992), em estudos anteriores sobre as crenças de professores. 
Acreditamos que essa tendência a crenças curriculares tradicionais entre os novatos, deva-se ao que Ariza (1995) apontou: quando esses tomam contato com a prática tendem a tomar um 'choque' ao verificar que têm dificuldade de aplicar seu modelo de ensino e não têm recursos pessoais para tal. Nesse caso, tendem a abandonar as crenças inovadoras e passam a utilizar aquelas centradas em tarefas de controle, organização e execução do ensino, portanto, mais tradicionais.

Também Marcelo (2009) cita que a maioria dos professores iniciantes têm pouco domínio dos conhecimentos que ensina, o que os faz retomar à maneira como aprenderam enquanto eram estudantes. E mais, segundo esse autor,

[...] as principais tarefas com que se deparam os professores principiantes são: adquirir conhecimentos sobre os estudantes, o currículo e o contexto escolar; planejar adequadamente o currículo e o ensino; começar a desenvolver um repertório docente que lhes permita sobreviver como professor; criar uma comunidade de aprendizagem na sala de aula (MARCELO, 2009, p.128).

Por outro lado, esses resultados também sinalizam para a necessidade de tratar das crenças curriculares na formação continuada dos formadores, para que essas possam ser ressignificadas por esses. Estévez-Nenninger e colaboradores (2014) apontam que a formação continuada e valorização das experiências profissionais são importantes para alteração das crenças dos professores. Porém, acreditamos que para esse coletivo de professores seria um processo mais demorado uma vez que $89 \%$ dos professores que respondeu ao questionário é discordante com a afirmativa 18, 'Seu modelo didáticopedagógico teve influência dos cursos de formação continuada (na sua área ou na área pedagógica) que você realizou ao longo da atuação docente'. O que mostra que os cursos de formação continuada não estão atingindo os professores dessas áreas.

Acreditamos que se o formador tiver crenças curriculares mais construtivistas evitará tratar a Ciência como sendo 'neutra', construída por 'gênios', "ahistórica" e acrítica, a qual é baseada no modelo empirista-indutivista e positivista ainda presente na Educação Científica e Tecnológica (CACHAPUZ et al., 2011).

Agradecimento: À Coordenação de Aperfeiçoamento de Pessoal de Nível Superior (CAPES), pelo apoio financeiro concedido.

\section{Referências}

APPLE, M. Ideologia e Currículo. 3 ed. Porto Alegre: Artmed, 2006. 
ARIZA, R. Las creencias pedagógicas y científicas de los profesores. Enseñanza de la ciencia de la tierra, s. 1., v. 3, n.1, p.7-13, 1995.

BARCELOS, A. M. Metodologia de Pesquisa das Crenças sobre Aprendizagem de Línguas: Estado da Arte. Revista Brasileira de Linguiística Aplicada, s. 1., v. 1, n. 1, p. 71-92, 2001.

BECKER, F. Epistemologia do professor: o cotidiano da escola. 16 ed. Petrópolis, RJ: Vozes, 2013.

BRASIL. Resolução n ${ }^{0}$ 01, de 18 de fevereiro de 2002a. Institui as Diretrizes Curriculares Nacionais para a Formação de Professores da Educação Básica, em nível superior, curso de licenciatura, de graduação plena. Brasília, DF.

BRASIL. Resolução no 09, de 11 de março de 2002b. Estabelece as Diretrizes Curriculares para os cursos de Bacharelado e Licenciatura em Física. Brasília, DF.

BRASIL. Resolução no 07, de 11 de março de 2002c. Estabelece as Diretrizes Curriculares para os cursos de Ciências Biológicas (Bacharelado e Licenciatura). Brasília, DF.

BRASIL. Resolução no 08, de 11 de março de 2002d. Estabelece as Diretrizes Curriculares para os cursos de Bacharelado e Licenciatura em Química. Brasília, DF.

BRASIL. Resolução $\mathbf{n}^{\circ}$ 03, de 18 de fevereiro de 2003. Estabelece as Diretrizes Curriculares para os cursos de graduação em Matemática. Brasília, DF.

BZUNECK, J. A.; BORSATO, E. Tendências Contemporâneas no Estudo de Crenças Educacionais de Professores e de Alunos de Licenciaturas. In: II SEMINÁRIO DE PESQUISA EM EDUCAÇÃO DA REGIÃO SUL (FORUM SUL DA ANPED), 1999, Curitiba. Anais... v. $1,1999$.

CACHAPUZ, A.; GIL-PEREZ, D.; CARVALHO, A. M.; PRAIA, J. VILCHES, A. A necessária renovação do ensino das ciências. 2. ed., São Paulo: Cortez, 2011.

COSTA, F.; ZANIN, A.; OLIVEIRA, T.; ANDRADE, M. As visões distorcidas da Natureza da Ciência sob o olhar da História e Filosofia da Ciência: uma análise dos anais do ENEQ e ENEBIO de 2012-2014. Actio, Curitiba, v. 2, n. 2, p. 4-20, 2017.

CRAHAY, M.; WANLIN, P.; ISSAIEVA, E.; LADURON, I. Funções, estruturação e evolução das crenças (e conhecimentos) dos professores. Cadernos Cenpec. São Paulo, v.6, n.2, p.316388, jul./dez. 2016.

DÍAZ, J.; ALONSO, A.; MÁS, M. A.; ROMERO, P. Persistencia de lasatictudes y creencias CTS em La profisión docente. Revista Eletrónica de Enseñansa de las Ciencias, s. 1., v.1, n.1., p.1-27, 2002.

DE JUANAS, A. O. Las creencias epistemológicas desde la perspectiva del aprendizaje de los estudiantes. 2012. Disponível em: https://www.researchgate.net/publication/257938090 Acesso em: 29 de jan de 2018.

ESTÉVEZ-NENNINGER, E. H, VALDÉS-CUERVO, A. A., ARREOLA-OLIVARRÍA, C. G.; ZAVALA-ESCALANTE, M. G. Creencias sobre enseñanza y aprendizaje en docentes universitarios. Revista Internacional de Investigación en Educación, s. 1., v.6, n.13, p.49-64, 2014. 
FUNDA SAVASCI-ACIKALIN. Teacher beliefs and practice in science education. AsiaPacificForum on Science Learning and Teaching, s. 1., v.10, i.1, article 12, p. 1-12, jun., 2009.

GIL PÉREZ, D.; MONTORO, I. F.; ALÍS, J.; PRAIA, J. Para uma imagem não deformada do trabalho científico. Ciência e Educação, s. 1., v.7, n. 2, p.125-153, 2001.

GIMENO SACRISTÁN, J. O currículo: uma reflexão sobre a prática. 3 ed. Porto Alegre Artmed, 2000.

GONÇALVES, D. Concepções científicas e concepções pessoais sobre o conhecimento e dificuldade de aprendizagem. 329 p. Tese (doutorado). Universidade de Lisboa. Faculdade de Psicologia e Ciências da Educação. Lisboa, 2002. Disponível em:

<http://www.lispsi.pt/Public/index.htm>. Acesso em: 02 de maio de 2017.

HUBERMAN, M. O ciclo de vida profissional dos professores. In: NÓVOA, A. (org). Vidas de professores. 2 ed., Portugal: Porto Ed., 1995, p.31- 62.

ISAIA, S.; MACIEL, A.M.; BOLZAN, D. P. Pedagogia universitária: desafio da entrada na carreira docente. Educação, Santa Maria, v. 36, n. 3, p. 425-440, set.- dez., 2011.

JUNIOR, P. D. Professor em início de carreira: crenças e conflitos. Em: ENCONTRO NACIONAL DE PESQUISA EM EDUCAÇÃO EM CIÊNCIAS (ENPEC), 7. 2009. Florianópolis/SC. Anais..., Florianópolis/SC, 2009, p. 1-11.

LOPES, A. C. Currículo e epistemologia. Ijuí: Editora UNIJUÍ, 2007.

MACHADO, L. C. Formação, Saberes e Práticas de Formadores de Professores: Um Estudo em Cursos de Licenciatura em História e Pedagogia. 2009. 292f. Tese (Doutorado em Ciências Humanas) - Universidade Federal de Uberlândia, Uberlândia. 2009.

MARCELO, C. A identidade docente: constantes e desafios. Revista Formação Docente, Belo Horizonte, v. 01, n. 01, p. 109-131, ago - dez, 2009. Disponível em:

<http://formacaodocente.autenticaeditora.com.br>. Acesso em: 10 set. 2016.

MARSULO, M.; DA SILVA, R. M. Os métodos científicos como possibilidade de construção de conhecimentos no ensino de Ciências. Revista Electrónica de Enseñanza de las Ciencias, s.l.,v. 4, n.3, p. 1-12, 2005.

MICCOLI, L. Experiências, crenças e ações: uma relação estreita na sala de aula em Língua estrangeira. In: DA SILVA, K. (org). Crenças, Discursos e Linguagem. Campinas: SP, Pontes, 2010.

MIZUKAMI, M. G. N. Aprendizagem da docência: professores formadores. Revista Ecurriculum, São Paulo, v. 1, n. 1, p. n. p., dez.-jul., 2006.

MORAES, R. É possível ser construtivista no ensino de Ciências? In: MORAES, R. (Org.). Construtivismo e ensino de ciências: reflexões epistemológicas e metodológicas. Porto Alegre/RS: EDIPUCRS, 2000, p. 103-129.

PAJARES, F. Teachers` beliefs and educational research: cleaning up a messy construct. Review of Educational Research, s. 1., v. 62, n.3, p.307-332, 1992. 
PALMA, S. Creencias curriculares y creencias de actuación curricular de los profesores de ciencias chilenos. Revista Electrónica de Enseñanza de las Ciencias, s. 1., v.8, n.2, p.505-526, 2009.

PRAIA, J.; CACHAPUZ, F. Um analisis de lãs concepciones acerca Del conocimento cientifico de los profesores portugueses de La enseñanza secundária. Revista Investigación y experiencias didácticas, s. 1., v.12, n3, p.350-354, 1994.

RAMÍREZ, E. Concepciones curriculares del profesorado de Física y Quimicaenformación inicial. Tese (Doutorado em Didáctica de las Ciencias experimentales y sociales: un Enfoque Interdisciplinar). Universidade de Sevilla, Faculdad de Ciência de laEducación, Sevilla, 2005.

SOUZA, C. E. Formadores de professores no ensino superior: olhares para trajetórias e ações formativas. 2011.331f. Tese (Doutorado em Ciências Humanas) - Universidade Federal de Uberlândia, Uberlândia, 2011.

SHULMAN, L. Conhecimento e ensino: fundamentos para a nova reforma. Cadernos Cenpec, s. 1., v.4, n.2, p.196-229, dez. 2014.

TARDIF, M. Saberes docentes e formação profissional. 17. ed., Petrópolis, RJ: Vozes, 2014.

TOBIN, K.; McROBBIE, C. Belifies about the Nature of Science and enacted Science curriculum. Science \& Education, s. 1., n.6, p.355-371, 1997.

Recebido em: 13 de julho de 2018.

Aceito em: 10 de agosto de 2018. 